\title{
Histologic and In Situ Viral Findings in the Myocardium in Cases of Sudden, Unexpected Death
}

Adina M. Cioc, M.D., Gerard J. Nuovo, M.D.

Department of Pathology, Ohio State University Medical Center, Columbus, Ohio

The purpose of this study was to do in situ viral detection in myocardial tissues of individuals who suffered sudden unexpected death and to correlate the results with the postmortem histopathologic findings. Thirteen cases were identified and the heart tissues were analyzed for adenovirus, cytomegalovirus, Epstein Barr virus, herpes simplex virus 1 and 2, human immunodeficiency virus 1 (HIV1), influenza $A$, influenza $B$, parvovirus, rotavirus, picornavirus (including separate primers for enterovirus and Coxsackie virus $A$ and $B$ ), varicella zoster virus, and respiratory syncytial virus. Thirteen individuals aged 2 to 67 years were studied. In each case, polymerase chain reaction-amplified viral RNA was detected in situ: Coxsackie virus B (5 cases), rotavirus ( 4 cases), HIV-1 ( 2 cases), influenza A (1 case), and influenza B ( 1 case). Immunohistochemical detection of viral proteins was found in the five Coxsackie virus cases and four rotavirus cases. The mononuclear inflammatory infiltrate was diffuse and marked only in the cases of influenza A and HIV-1, as well as one of the Coxsackie virus and rotavirus cases, respectively. Immunohistochemical analysis showed that the most common cell type in the inflammatory infiltrates was CD68positive macrophages. Direct myocyte infection was most prominent in the cases of Coxsackie virus infection. In summary, in situ viral detection was documented in each case of idiopathic myocarditis associated with sudden, unexpected death; in $6 / 13$ cases, the myocarditis was focal and minimal. Although Coxsackie virus was, as expected, the most common virus noted, other viruses including rotavirus and HIV-1 were also observed, highlighting

\footnotetext{
Copyright () 2001 by The United States and Canadian Academy of Pathology, Inc.

VOL. 15, NO. 9, P. 914, 2001 Printed in the U.S.A.

Date of acceptance: May 1, 2002.

Supported by a grant from the Lewis Foundation (G.J.N.).

Address reprint requests to: Gerard J. Nuovo, M.D., Department of Pathology, The Ohio State University Medical Center, S305E Rhodes Hall, 450 W 10th Avenue, Columbus, OH 43210; e-mail: gnuovomd@pol.net; fax: 614-293-4715.

DOI: 10.1097/01.MP.0000024291.37651.CD
}

the need for comprehensive viral and histologic analyses in such cases.

KEY WORDS: Coxsackie, HIV-1, In situ, Myocarditis, PCR, Rotavirus.

Mod Pathol 2001;15(9):914-922

Sudden, unexpected, idiopathic death is a clinicopathologic diagnosis that typically involves a previously healthy person who dies suddenly, with no definitive cause of death found at the autopsy (1). These cases represent a substantial proportion of forensic autopsies, $>8 \%$ in some series (1). It is highly likely that some cases of sudden death are associated with viral infections. Indeed, it is estimated that $\geq 5 \%$ of any virus-infected population experiences some cardiovascular symptoms, and higher proportions may be encountered during epidemics (2).

Although virâl myocarditis is usually a chronic disease associated with end-stage heart failure, it is well documented that it can also be associated with sudden, unexpected death $(1,3-6)$. The mode of death probably involves arrhythmias because the degree of myocyte necrosis and damage in acute viral myocarditis is often not sufficient to induce cardiac failure $(4,5)$. Even when acute fatal viral myocarditis is strongly suspected on the basis of the clinical and pathologic findings, it is often difficult to diagnose the etiologic agent (7). The members of the genus Enterovirus (family Picornaviridae) are the most commonly implicated in viral myocarditis $(2,6,8-9)$. Coxsackie B virus may account for nearly $50 \%$ of cases of documented viral myocarditis (8). Many other viruses are associated with viral myocarditis, including Coxsackie A, influenza A, cytomegalovirus, and adenovirus, as well as other viruses $(6,8)$.

Although human immunodeficiency virus 1 (HIV-1) infection may be associated with cardiac complications, usually this association is noted in people with long-standing acquired immune deficiency syndrome (AIDS; 10). However, it has been shown that HIV-1 is directly associated with AIDS myopathy, primarily via infection of macrophages 
infiltrating the involved skeletal muscles (11). It is possible that HIV-1 could also be associated with acute myocarditis before the development of AIDS, although to our knowledge, this has not been documented using in situ-based methodologies.

Detection of viruses associated with myocarditis is problematic for several reasons. In cases of sudden, unexpected death, serology is usually not available, and viral cultures have relatively low sensitivity, especially in the autopsy setting (8). In situ hybridization analyses for DNA viruses, which are associated with high copy number, show both high sensitivity and specificity, as documented in cases of cytomegalovirus and adenovirus-associated myocarditis (12-14). However, most cases of viral myocarditis are associated with RNA viruses, in which the viral genome number may be below the detection threshold of the assay, which is about 10 copies per cell (15-17). This problem can be circumvented by using reverse transcriptase in situ polymerase chain reaction (RT in situ PCR). This methodology allows the use of inexpensive, longlasting oligoprimers and, as it is optimized with formalin-fixed tissues, obviates concerns of testing for potentially dangerous viruses with unfixed tissues that are optimal for solution phase PCR analyses (15-17). The purposes of this study are to determine both the presence and specific types of virus that can be detected by in situ hybridizationbased techniques in the myocardium of individuals who suffered sudden unexpected death and to correlate the viral results with the histopathologic findings.

\section{MATERIALS AND METHODS}

\section{Selection of Cases}

The study originated with cases sent by various medical examiners in which a thorough autopsy with toxicology and clinical correlates produced no convincing cause of death, although viral myocarditis was suspected. In each of these five cases, the heart was normal grossly (including no congenital heart disease, no evidence of coronary artery or valve disease, and normal heart weight), and the microscopy varied from "rare, focal chronic inflammation" to unequivocal chronic myocarditis. We then attempted to obtain similar cases from the autopsy archives from 1995-2000 at the Ohio State University Department of Pathology. The selection criteria were that there was no definitive cause of death based on the gross and histologic autopsy findings and that myocarditis was considered in the differential diagnosis, either clinically or histologically. Eight cases were identified. In each case, there was no clinical or pathological evidence of congenital heart disease, coronary arteritis, pericar- dial disease, or endocarditis. Only one person had evidence of coronary artery disease $(80 \%$ occlusion of three vessels, Case 11; Table 1). Further, only one person had valve disease (tricuspid valve replacement, Case 12; Table 1). In neither case was the preexisting heart disease thought to be sufficient to explain the person's death. The weight of the heart was listed as within normal limits except for in Cases 9 (520 g) and 11 (740 g; Table 1). In each of the 12 cases, only paraffin-embedded, formalinfixed tissue was available.

We included 10 negative controls in this study; 5 were heart tissues from people who died of acute trauma, and the other 5 cases were cardiac tissues from people who died cancer-related deaths. The selection criteria for the 10 negative controls were that the entire gross and histologic examination of the heart tissue at autopsy was within normal limits.

\section{In Situ Hybridization}

In situ hybridization was performed using a previously published protocol (15-17). In brief, multiple $4-\mu \mathrm{m}$ sections were obtained and placed on silane-coated glass slides. This allowed direct comparison of the hematoxylin and eosin stain results with the viral findings. The tissue was deparaffinized and proteased (30 $\mathrm{min}$ in $2 \mathrm{mg} / \mathrm{mL}$ of pepsin) The - probes, each from Enzo Diagnostics (Farmingdale, NY) included adenovirus, EpsteinBarr virus, cytomegalovirus, herpes simplex virus Types 1/and 2, and parvovirus. The probe cocktails containing the biotin-labeled probe and tissue DNA were codenatured at $95^{\circ} \mathrm{C}$ for 5 minutes, hybridized

TABLE 1. Histologic Findings in the Myocardium in Cases of Sudden, Unexpected Death

\begin{tabular}{|c|c|c|c|}
\hline Age (y)/Sex & Myocyte Necrosis $^{a}$ & $\begin{array}{c}\text { Interstitial } \\
\text { Inflammation }^{b}\end{array}$ & $\begin{array}{l}\text { Perivascular } \\
\text { Infiltration }^{c}\end{array}$ \\
\hline $21 / \mathrm{M}$ & rare & marked & diffuse \\
\hline $47 / \mathrm{M}$ & marked & marked & diffuse \\
\hline $24 / \mathrm{M}$ & absent & marked & diffuse \\
\hline $43 / \mathrm{M}$ & rare & rare & focal \\
\hline $2 / \mathrm{M}$ & absent & rare & focal \\
\hline $6 / \mathrm{M}$ & absent & marked & focal \\
\hline $37 / F$ & marked & marked & diffuse \\
\hline $62 / \mathrm{F}$ & absent & rare & focal \\
\hline $60 / \mathrm{M}$ & rare & rare & focal \\
\hline $52 / \mathrm{F}$ & marked & marked & focal \\
\hline $67 / \mathrm{M}$ & rare & marked & diffuse \\
\hline $44 / \mathrm{F}$ & rare & minimal & focal \\
\hline $25 / \mathrm{F}$ & absent & rare & focal \\
\hline
\end{tabular}

$\mathrm{M}$, male; F, female.

${ }^{a}$ Myocyte necrosis: absent, rare: 1 to 5 degenerated myocytes per tissue section; moderate: 6 to 10 degenerated myocytes per tissue section; marked: $>11$ necrotic myocytes per tissue section.

${ }^{b}$ Interstitial inflammation: absent, minimal: 1 to 3 areas of interstitial infiltrates; marked: $\geq 4$ or more areas of interstitial infiltrates.

${ }^{c}$ Perivascular infiltration: absent, focal: 1 to 3 areas of perivascular infiltrates per tissue section; diffuse: $\geq 4$ areas of perivascular infiltrates per tissue section. 
for 2 hours at $37^{\circ} \mathrm{C}$, then washed at high stringency $\left(\mathrm{Tm}-5^{\circ} \mathrm{C}\right)$, followed by localization of the probetarget complex by the action of alkaline phosphatase on the chromogen nitroblue tetrazolium and bromochloroindoyl phosphate. Nuclear fast stain served as the counterstain.

\section{Reverse Transcriptase In Situ PCR}

The protocol used has been previously described (15-17). Briefly, optimal protease digestion time was first determined using the nonspecific incorporation of the reporter nucleotide as the guide (10 $\mu \mathrm{mol} / \mathrm{L}$ digoxigenin deoxyuridine triphosphate [dUTP]). Optimal protease digestion was followed by overnight incubation in RNase-free DNase (10 U pre sample, Boehringer Mannheim, Indianapolis, IN) and one-step RT-PCR using the rTth system and digoxigenin dUTP, as described previously (15-17). All tissues were analyzed for the following viruses: picornavirus (which can detect enterovirus, rhinovirus, and other viruses including hepatitis A), influenza $A$ and $B$, respiratory syncytial virus, varicella zoster virus, HIV-1, and rotavirus. The cases positive for picornavirus were then tested with consensus primers for enterovirus and, if positive, then tested using primers that are specific for Coxsackie virus $A$ and $B(18,19)$.

Positive controls for each virus were available from the files of one of the authors (G.J.N.) and gave the expected results (data not shown). Negative controls included heart tissue sections from 10 different people with no evidencê (grossly or histologically) of cardiac disease, as described above. All the probes tested on these tissues were negative (data not shown). For the RNA viruses, an additional control was pretreatment with RNase before reverse transcriptase (16). The loss of the signal confirmed that it was RNA based.

\section{Immunohistochemistry}

Our protocol has been previously published (8, $10,12)$. In brief, after deparaffinization, sections were incubated with CD45 or CD68 (DAKO, Carpinteria, CA). Each of the 13 cases was also tested by immunohistochemistry for enteroviral and rotaviral protein using a previously published method (1820). The antigen-antibody complex was detected using the SuperSensitive peroxidase based kit of Biogenex (San Roman, CA), as per the manufacturer's protocol. Dilute hematoxylin served as the counterstain to the brown signal induced by the chromogen 3,3'-diaminobenzidine.

\section{RESULTS}

Thirteen individuals, aged 2 to 67 years, each of whom suffered sudden, unexpected death, were in- cluded in this study. Nine of the 13 were males. Two of the people were children (aged 2 and 6 y) and were the subject of a previous report (20). The 11 adults ranged in age from 21 to 67 years, with a mean age of 42 years.

The histologic features of the myocardium from the 13 cases were analyzed. The variables that were studied were as follows: myocyte necrosis (absent, rare: 1 to 5 degenerated myocytes per tissue section; moderate: 6 to 10 degenerated myocytes per tissue section; and marked: $>10$ necrotic myocytes per tissue section), perivascular infiltration (absent, focal: 1 to 3 areas of perivascular infiltrates per tissue section; diffuse: $\geq 4$ areas of perivascular infiltrates per tissue section), interstitial inflammation (absent, minimal: 1 to 3 areas of interstitial infiltrates; marked: $\geq 4$ areas of interstitial infiltrates). The inflammatory infiltrates, which consisted primarily of cells with the cytologic features of macrophages and, to a lesser extent, lymphocytes, had to contain $\leq 10$ mononuclear cells to be scored using the above system. Case 2 (Table 1) showed a diffuse increase in eosinophils, although the cells with the cytologic features of activated macrophages still predominated. Neither plasma cells nor aggregates of neutrophils were evident in any of the tissues. A summary of the histologic findings is presented in Table 1. Note that in five of the cases there was no evidence of myocyte necrosis and that only five cases showed marked and diffuse mononuclear cell infiltrates.

Although on routine histologic analysis it was evident that most of the cells in the perivascular and interstitial infiltrates had the cytologic appearance of macrophages, immunohistochemistry was done for CD45 and CD68 to further elucidate the phenotype of the cells in the inflammatory infiltrates. These analyses showed that the mononuclear cell infiltrates were indeed dominated by CD68 positive cells, that is, macrophages. The range of CD68-positive cells in the perivascular and interstitial infiltrates was 36 to $89 \%$, with a mean of $69 \%$. In most of the other cases, the remaining mononuclear cells in the infiltrates were lymphocytes.

The tissues were next analyzed for adenovirus, cytomegalovirus, Epstein-Barr virus, herpes simplex virus 1 and 2, HIV-1, influenza A, influenza B, parvovirus, rotavirus, picornavirus (including separate primers for enterovirus and Coxsackie virus $A$ and B), varicella zoster virus, and respiratory syncytial virus. Analysis was done using either in situ hybridization (for DNA viruses) or RT in situ PCR (for RNA viruses). None of the 13 tissues contained a DNA virus, which was the expected finding as most of these viral infections are associated with inclusions that are readily recognized on histologic examination (15-17), and none of the 13 cases had evidence of viral inclusions. An RNA virus was 
found in each of the cases. In 5 of the cases, the picornavirus probe yielded a signal. Further analysis demonstrated a signal in each case with the enterovirus consensus probe. Each of these cases was positive with the Coxsackie virus $B$ probe and negative with the Coxsackie virus A probe. Of the eight other cases, HIV-1 was detected in two, influenza A in one, influenza B in another, and rotavirus in the other four cases. In one of the rotavirus cases, the virus was isolated by culture of a stool sample. In the two HIV-1 cases, additional tissues (spleen and lymph nodes) were examined by in situ PCR and solution phase PCR, and each documented the presence of the virus (data not shown). Serology documented the infection immediately before death in the one influenza B and one influenza A case. Figures 1, 2, and 3 show representative examples of myocardial infection by HIV-1, Coxsackie B virus, and rotavirus, respectively. Note the predom- inance of the CD68-positive macrophages in the inflammatory infiltrates that contained many of the viral infected cells (Figs. 2 and 3 ).

A compilation of the viral results as determined by RT in situ PCR relative to the different cases is provided in Table 2, which also lists the cells that were infected by the virus. Note that direct myocyte infection was most associated with infection by Coxsackie B virus (Fig. 2), although one case each of HIV-1 infection and rotavirus myocarditis did show rare infected myocytes. Further, in the four rotavirus-positive cases, the virus showed a strong predilection for endothelial cells and was also found in monocytes (Fig. 3). We next performed immunohistochemistry on the 13 tissues for rotavirus and enteroviral-specific proteins. Nine of the tissues yielded a positive signal, with five cases that were positive for Coxsackie virus RNA also positive for the enteroviral VP1 protein (Fig. 2) and the four

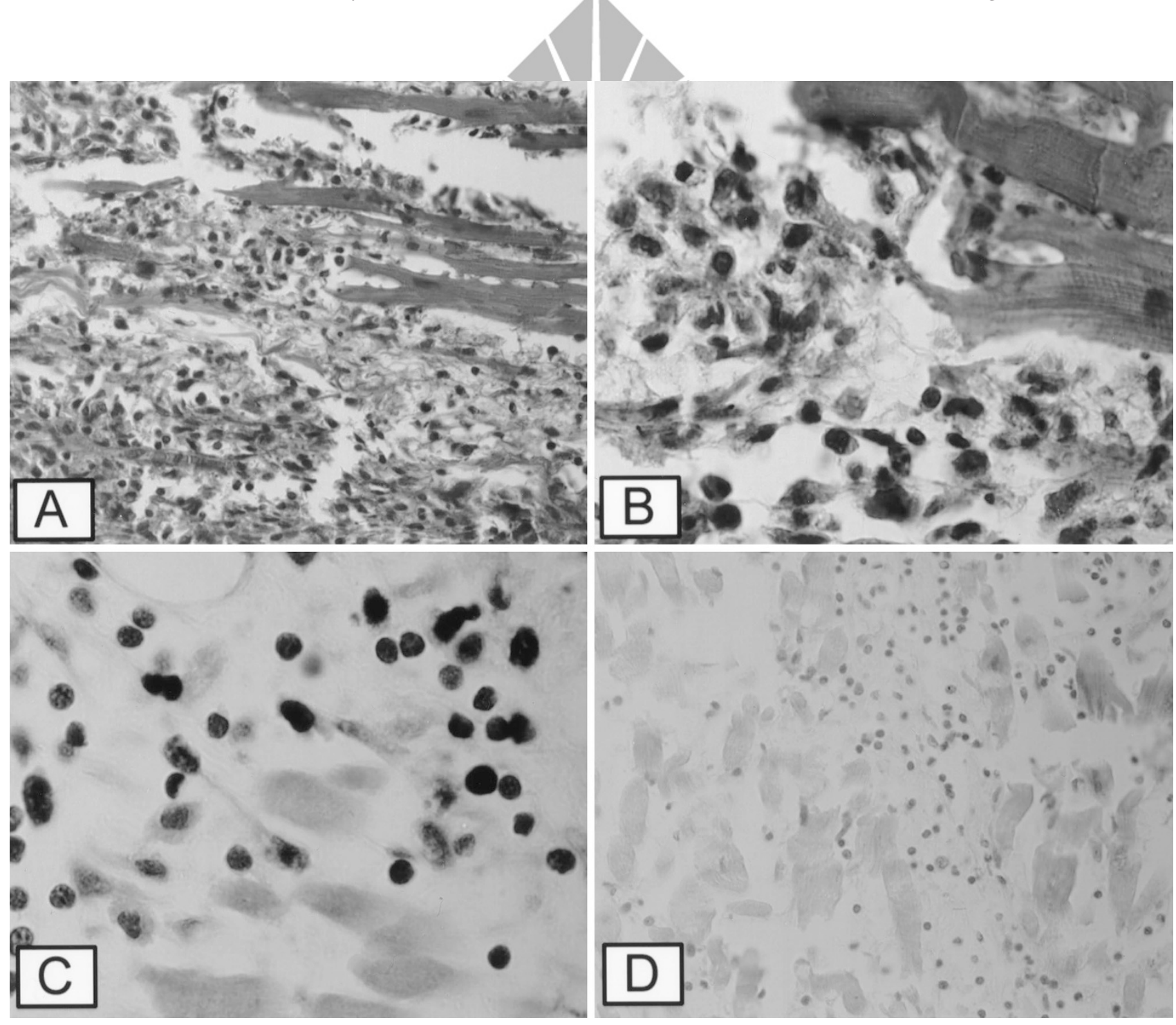

FIGURE 1. Histologic and viral findings in human immunodeficiency virus 1 (HIV-1) myocarditis. A, the histologic findings at low magnification in Case 1. Note the interstitial inflammatory infiltrate. At higher magnification (B), cells with the cytologic features of macrophages are evident. Many of these cells colabeled with CD68 (not shown). HIV-1 RNA was detected in many of these cells by reverse transcription (RT) in situ polymerase chain reaction (PCR; C); the signal was lost if RNase digestion preceded the RT in situ PCR (D). 

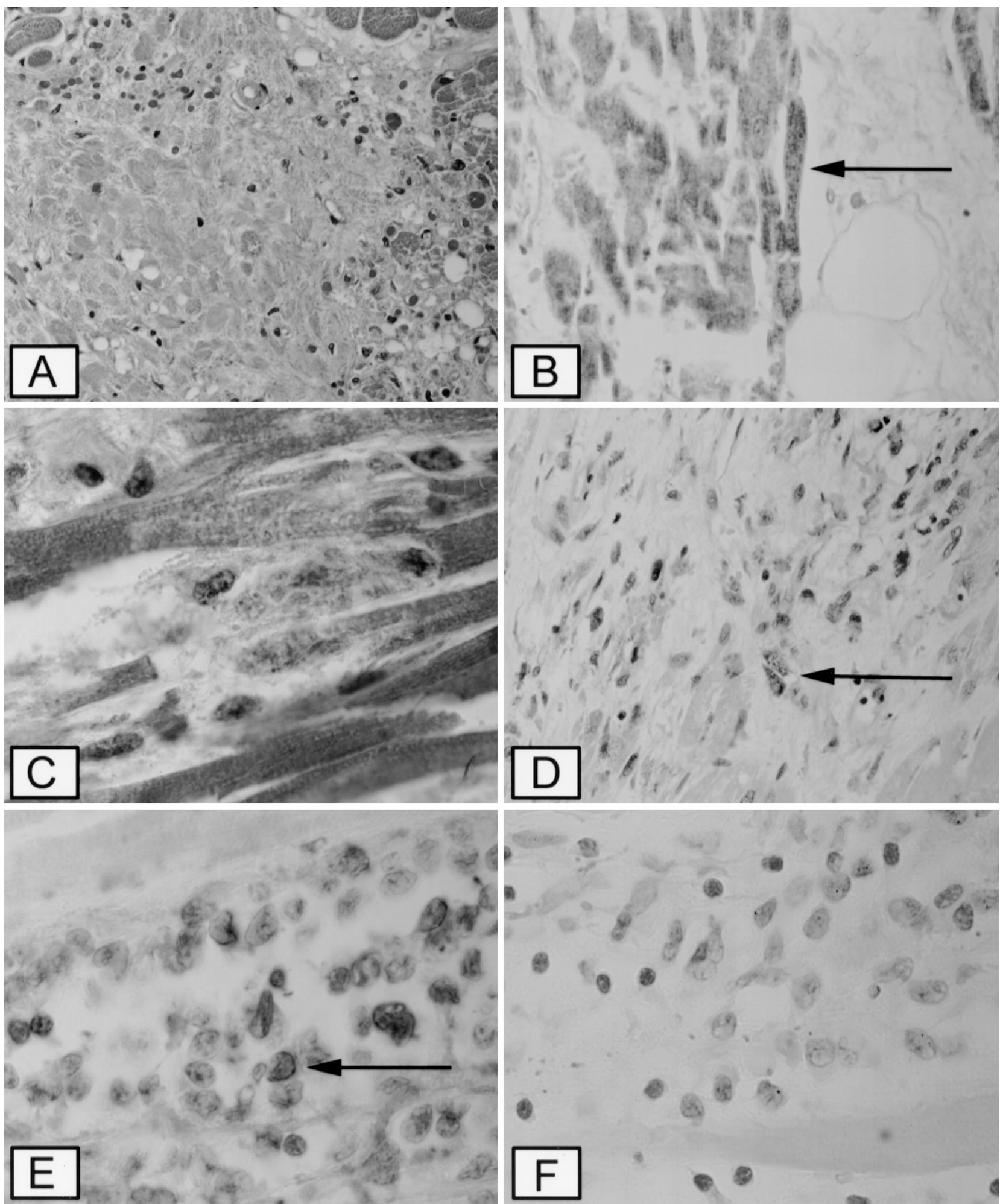

FIGURE 2. Histologic and viral findings in Coxsackie virus B myocarditis. A, an area of extensive necrosis of myocytes in Case 7.

Immunohistochemical analysis using a consensus enteroviral antibody demonstrated myocyte infection in this case and each of the other Coxsackie virus cases (B, arrow). In other areas, interstitial infiltrates contained cells with hemosiderin pigment and the cytologic features of macrophages (C, Case 4). D \& E, Case 10; note that many of the cells in a focus of interstitial inflammation showed a signal using CD68 (D, arrow); cells with similar cytologic features contained Coxsackie virus B RNA as determined by RT in situ PCR (E, arrow). F, another negative control, which is the lack of a signal with primers specific for Coxsackie virus A; similar results were evident with all the other viruses that were tested.

cases positive for rotaviral RNA also positive for rotavirus protein (Fig. 3). Although the geographic distribution was similar with immunohistochemis- try versus $\mathrm{RT}$ in situ PCR, the latter method showed $\geq 10$-fold increase in the number of positive cells, perhaps reflecting its higher sensitivity. 
TABLE 2. Viral Findings in the Myocardium in Cases of Sudden, Unexpected Death

\begin{tabular}{|c|c|c|c|}
\hline Age (y)/Sex & Virus & Viral Load $^{a}$ & Viral Targets \\
\hline $21 / \mathrm{M}$ & HIV-1 & $3+$ & macrophages $^{b}$ \\
\hline $47 / \mathrm{M}$ & influenza A & $3+$ & lymphocytes, macrophages \\
\hline $24 / \mathrm{M}$ & HIV-1 & $3+$ & macrophages \\
\hline $43 / \mathrm{M}$ & Coxsackie B & $3+$ & $\begin{array}{l}\text { myocytes, macrophages, } \\
\text { endothelial cells }\end{array}$ \\
\hline $2 / \mathrm{M}$ & rotavirus & $2+$ & endothelial cells \\
\hline $6 / \mathrm{M}$ & rotavirus & $2+$ & endothelial cells \\
\hline $37 / \mathrm{F}$ & Coxsackie B & $3+$ & myocytes \\
\hline $62 / \mathrm{F}$ & Coxsackie B & $2+$ & myocytes, endothelial cells \\
\hline $60 / \mathrm{M}$ & Coxsackie B & $2+$ & $\begin{array}{l}\text { myocytes, macrophages, } \\
\text { endothelial cells }\end{array}$ \\
\hline $52 / \mathrm{F}$ & Coxsackie B & $3+$ & $\begin{array}{l}\text { myocytes, macrophages, } \\
\text { endothelial cells }\end{array}$ \\
\hline $67 / \mathrm{M}$ & rotavirus & $3+$ & macrophages, endothelial cells \\
\hline $44 / F$ & rotavirus & $2+$ & macrophages, endothelial cells \\
\hline $25 / F$ & influenza B & $1+$ & macrophages \\
\hline
\end{tabular}

M, male; F, female; HIV-1, human immunodeficiency virus 1 .

${ }^{a}$ Viral load is defined as follows: $1+, 1-20$ viral infected cells per tissue section; 2+, 21-40 viral infected cells per tissue section; $3+,>40$ viral infected cells per tissue section.

${ }^{b}$ Macrophages as defined by the cytologic features and colabeling experiments using CD68 on serial sections to those used for viral analysis.

\section{DISCUSSION}

Myocarditis is a disorder that affects both pediatric and adult populations and that may present as an acute or chronic illness (21). In most patients, complete recovery without any sequelae may be expected (8). The term fulminant myocarditis is proposed for cases, typical of younger people, in which the development of myocarditis is heralded by a nonspecific flu-like illness and in which the onset of cardiac involvement determines a rapid deterioration in the patient/condition with profound hemodynamic compromise (3). Extensive inflammatory infiltrates are usually found in the hearts of these patients, in concert with ventricular dysfunction and abnormal electrocardiogram findings (4). Fulminant myocarditis has been found to be responsible for $6 \%$ of cases in a series of sudden, unexpected deaths (5). Five of our cases showed the marked and diffuse inflammatory infiltrates characteristic of this entity. However, to our knowledge, this is the first time that HIV-1 has been detected by an in situ-based assay in the myocardium in such a setting. Other studies have stressed that in addition to fulminant myocarditis, focal myocarditis is a common pathologic substrate of sudden cardiac death $(22,23)$, as is evident in most of the cases in this study. Cardiac inflammatory infiltrates were focal in 8/13 cases in our study. It is hypothesized that focal inflammatory infiltrates can precipitate fatal ventricular arrhythmias despite normal or minimally disturbed ventricular function $(4,5)$. Only 1 of the 13 people in this study had had any testing done on the conduction system (Case 8) and this was determined to be within normal limits.

The viral etiology of myocarditis is often difficult to establish with certainty in a given patient (8).
Isolation of the virus from noncardiac tissues, though presumptive evidence, does not establish its etiologic role in myocarditis. Clinical findings that are supported by serologic evidence of infection similarly allow only a presumptive diagnosis of myocarditis (8). The histologic findings in endomyocardial biopsies may be used in the diagnosis of viral myocarditis. However, there is considerable interobserver variation in the interpretation of histologic findings $(8,24)$. Moreover, as evidenced in this study, the histologic findings are often focal and minimal, and thus easily missed on a small endomyocardial biopsy $(25,26)$. Direct in situ detection of the virus in such a biopsy would be needed to establish the diagnosis. This study highlights the utility of RT in situ PCR in this regard, as each of the 13 positive cases contained an RNA virus. Further, the results of this study underline the importance of a comprehensive panel of viral probes, as five different viruses were detected in the cases included in our study. Although we did note that certain histologic changes were more consistent with specific viruses, for example a diffuse and marked myocarditis with HIV-1 infection, it is best to consider the histologic findings as not specific for a particular virus. Further, the focal nature of the inflammation accentuates the need for adequate sampling in the work-up of possible viral myocarditis.

Enteroviruses of the Picornaviridae, such as Coxsackie virus of Group B, are generally considered to be the most common cause of viral myocarditis (2, 6, 8, 9). Kandolf et al. (9) were the first to use in situ hybridization techniques in 1987 to demonstrate the presence of viral RNA in myocytes of Coxsackie virus B3-infected mice (24). Similar results were obtained in the hearts of patients with myocarditis and idiopathic dilated cardiomyopathy, where Coxsackie B virus-specific RNA was identified $(24,27)$. It was noted that the Coxsackie virus is found in myocytes and in small interstitial cells resembling myocardial fibroblasts (9); our study also demonstrated the ability of this virus to directly infect myocytes, which was much less commonly noted among the other viruses reported in this series. In a retrospective study based on autopsy material, another study used in situ hybridization and the polymerase chain reaction to demonstrate the presence of Coxsackie B RNA in archival material from five of six patients with acute myocarditis (28). Coxsackie virus was also demonstrated by Hilton et al. (29) using in situ hybridization in 2 of 10 cases of childhood myocarditis; in both cases, the signal was confined to myocytes and was not seen in inflammatory cells. The lack of detection in endothelial cells and inflammatory cells as compared with this study may reflect the greater sensitivity of RT in situ PCR versus in situ hybridization (15-17). Direct 

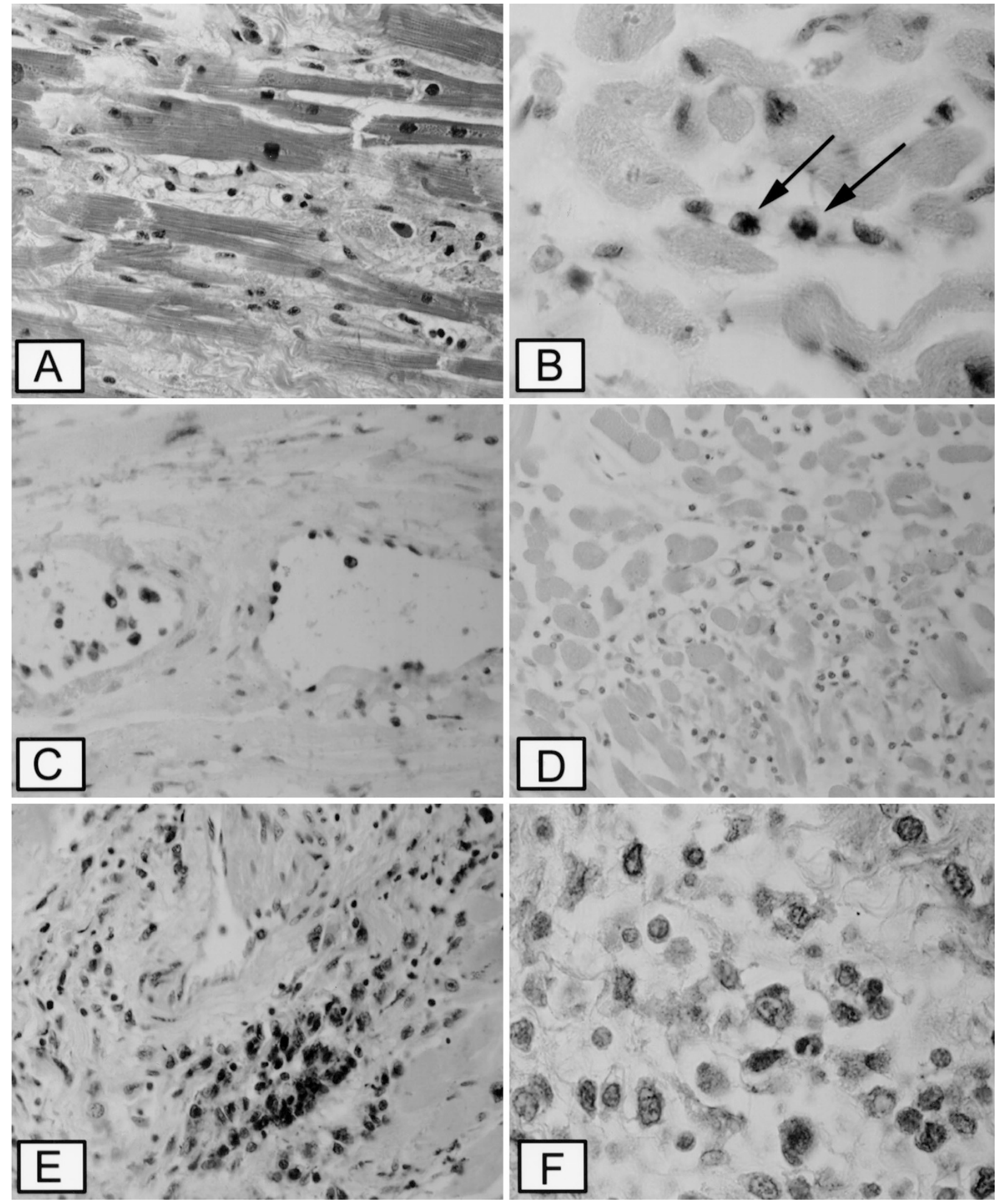

FIGURE 3. Histologic and viral findings in rotavirus myocarditis. A, a representative histologic field in Case 12, in which interstitial and perivascular infiltrates were minimal. However, many of the endothelial cells in this area contained rotaviral RNA as determined by RT in situ PCR (B, arrow). C, a representative field in Case 11; the RNA-based signal localized to endothelial cells and intravascular mononuclear cells in a larger caliber vessel. The signal was lost with pretreatment in RNase, demonstrating that it is RNA based (D). E, another field in Case 11; note the prominent inflammatory infiltrates in which many of the cells labeled with CD68. Many of these cells contained rotaviral protein as determined by immunohistochemistry (F); note the cytoplasmic localization.

myocyte infection is clearly not the essential feature of fatal viral myocarditis; even in the cases of Coxsackie B virus infection, the majority of the infected cells were the infiltrating mononuclear cells, many of which were likely macrophages, and endothelial cells. It is possible that these infected cells may be 
inducing cytokine production, either directly or in adjacent noninfected cells, which may be injurious to myocyte function and the conduction system; this will require further study. Interestingly, both rotavirus and Coxsackie virus-associated myocarditis were associated with a strong predilection for infection of the endothelial cell, suggesting in each case that receptors for the virus were present in these cells.

We have previously reported the two cases of fatal rotavirus myocarditis in children (20). In addition to the two childhood cases, two of our rotavirus cases were patients 44 and 67 years old, respectively. Fatal rotavirus-associated myocarditis to our knowledge has not been described in adults. Interestingly, the two adults with rotaviral myocarditis each had preexisting cardiac disease, suggesting that the viral infection may have worked in concert with the previous heart damage to precipitate the patient's death.

The involvement of HIV in myocarditis has been previously studied by in situ hybridization in HIVpositive patients, both with and without symptomatic heart disease (30). In one study, HIV-1 was identified by in situ hybridization in 5 of $33 \mathrm{HIV}$ positive patients evaluated for unexplained left ventricular dysfunction (30). Our two cases in which the presence of the HIV-1 genome is documented in the myocardium involved young individuals with no previous documented HIV-1 infection. To our knowledge, this is the first report of fatal HIV-1 myocarditis as the presenting illness of infection by this virus.

A case of fatal myocarditis associated with influenza A in a young patient has been previously described (6). The virus was identified in lung sections by in situ hybridization and immunohistochemical techniques. However, that study (6) failed to demonstrate the viral signal within inflammatory cells or necrotic myocytes in heart sections. We were able to document the localization of the viral RNA within the mononuclear inflammatory cells in both our influenza A and B cases, perhaps reflecting the greater sensitivity of the RT in situ PCR assay.

\section{REFERENCES}

1. Drescher J, Zink P, Verhagen W, Flik J, Milbradt H. Recent influenza virus A infections in forensic cases of sudden unexplained death. Arch Virol 1987;92:63-76.

2. Why H. Enteroviruses and myocarditis. Br J Hosp Med 1995; 53(9):430-4.

3. Lieberman EB, Hutchins GM, Herskowitz A, Rose NR, Baughman KL. Clinicopathologic description of myocarditis. J Am Coll Cardiol 1991;18(7):1617-26.

4. Corrado D, Basso C, Thiene G. Sudden cardiac death in young people with apparent normal heart. Cardiovasc Res 2001;50:399-408.
5. Wentworth P, Jentz LA, Croal AE. Analysis of sudden unexpected death in southern Ontario, with emphasis on myocarditis. Can Med Assoc J 1979;120:676-80, 706.

6. Nolte KB, Alakija P, Oty G, Shaw MW, Subbarao K, Guarner $\mathrm{J}$, et al. Influenza A virus infection complicated by fatal myocarditis. Am J Forensic Med Pathol 2000;21(4):375-9.

7. Nolte KB, Simpson GL, Parrish RG. Emerging infectious agents and the forensic pathologist: the New Mexico model. Arch Pathol Lab Med 1996;120:125-8.

8. Maze SS, Adolph RJ. Myocarditis: unresolved issues in diagnosis and treatment. Clin Cardiol 1990;13:69-79.

9. Kandolf R, Klingel K, Zell R, Canu A, Fortmüller U, Hohenadl $\mathrm{C}$, et al. Molecular mechanisms in the pathogenesis of enteroviral heart disease: acute and persistent infections. Clin Immunol Immunopathol 1993;68(2):153-8.

10. Milei J, Grana D, Fernandez Alonso G, Matturri L. Cardiac involvement in acquired immunodeficiency syndrome-a review to push action. The Committee for the Study of Cardiac Involvement in AIDS. Clin Cardiol 1998;21(7):46572 .

11. Seidman N, Peress N, Nuovo GJ. In situ detection of PCRamplified HIV-1 nucleic acids in skeletal muscle in patients with myopathy. Mod Pathol 1994;7:369-75.

12. Schönian U, Crombach M, Maisch B. Assessment of cytomegalovirus DNA and protein expression in patients with myocarditis. Clin Immunol Immunopathol 1993;68(2):229-

33.

13. Schönian U, Crombach M, Maser S, Maisch B. Cytomegalovirus-associated heart muscle disease. Eur Heart J 1995;16(Suppl O):46-9.

14. Pankuweit S, Portig I, Eckardt H, Crombach M, Hufnagel G, Maisch B. Prevalence of viral genome in endomyocardial biopsies from patients with inflammatory heart muscle disease. Herz 2000;25(3):221-6.

15. Nuovo GJ, Gallery F, MacConnell P. In situ detection of PCR-amplified HIV-1 nucleic acids and tumor necrosis factor RNA in the central nervous system. Am J Pathol 1994; 144:659-66.

16. Nuovo GJ. PCR in situ hybridization: protocols and applications. 3rd ed. New York: Lippincott-Raven; 1997.

17. Nuovo GJ. Histologic distribution of hepatitis A, B, C, D, E, and $\mathrm{G}$ with concomitant cytokine response in liver tissue. Diagn Mol Pathol 1998;7:267-75.

18. Euscher E, Davis J, Holtzman I, Nuovo GJ. Coxsackie virus infection of the placenta associated with neurodevelopmental delays in the newborn. Obstet Gynecol 2001;98:1019-26.

19. Severini GM, Mestroni L, Falaschi A, Camerini F, Giacca M. Nested polymerase chain reaction for high sensitivity detection of enteroviral RNA in biological samples. J Clin Microbiol 1993;31:1345-9.

20. Morrison C, Gilson T, Nuovo GJ. Histologic correlates of fatal rotaviral infection. Hum Pathol 2001;32:216-21.

21. Micevski V. The use of molecular technologies for the detection of enteroviral nucleic acid in myocarditis. J Cardiovasc Nurs 1999;13(4):78-90.

22. Gore I, Saphir O. Myocarditis: a classification of 1402 cases. Am Heart J 1947;34:827-30.

23. Luke JL, Helpern M. Sudden unexpected death from natural causes in young adults: a review of 275 consecutive autopsied cases. Am J Pathol 1968;85:10-17.

24. Burke M. Viral myocarditis. Histopathology 1990;17:193-200.

25. Dec GW, Fallon JT, Southern JF, Palacios IF. Relation between histological findings on early repeat right ventricular biopsy and ventricular function in patients with myocarditis. Br Heart J 1988;60:332.

26. Marboe CC, Schwartz RA, Adelson D, Escala EL, Weiss MB, Fenoglio JJ. Active myocarditis with fibrosis. Poor correlation 
of ejection fraction with histology of follow-up biopsy. Eur Heart J 1987;8:43.

27. Tracy S, Chapman NM, McManus BM, Pallansch MA, Beck MA, Carstens J. A molecular and serologic evaluation of enteroviral involvement in human myocarditis. J Mol Cell Cardiol 1990;22:403-14.

28. Nicholson F, Ajetunmobi JF, Li M, Shackleton EA, Starkey WG, Illavia SJ, et al. Molecular detection and serotypic analysis of enterovirus RNA in archival specimens from patients with acute myocarditis. Br Heart J 1995;74:522-7.
29. Hilton DA, Variend S, Pringle JH. Demonstration of Coxsackie virus RNA in formalin-fixed tissue sections from childhood myocarditis cases by in situ hybridization and the polymerase chain reaction. J Pathol 1993;170: 45-51.

30. Herskowitz A, Wu TC, Willoughby SB, Vlahov D, Ansari AA, Beschorner WE, et al. Myocarditis and cardiotropic viral infection associated with severe left ventricular dysfunction in late-stage infection with human immunodeficiency virus. J Am Coll Cardiol 1994;24(4):1025-32.

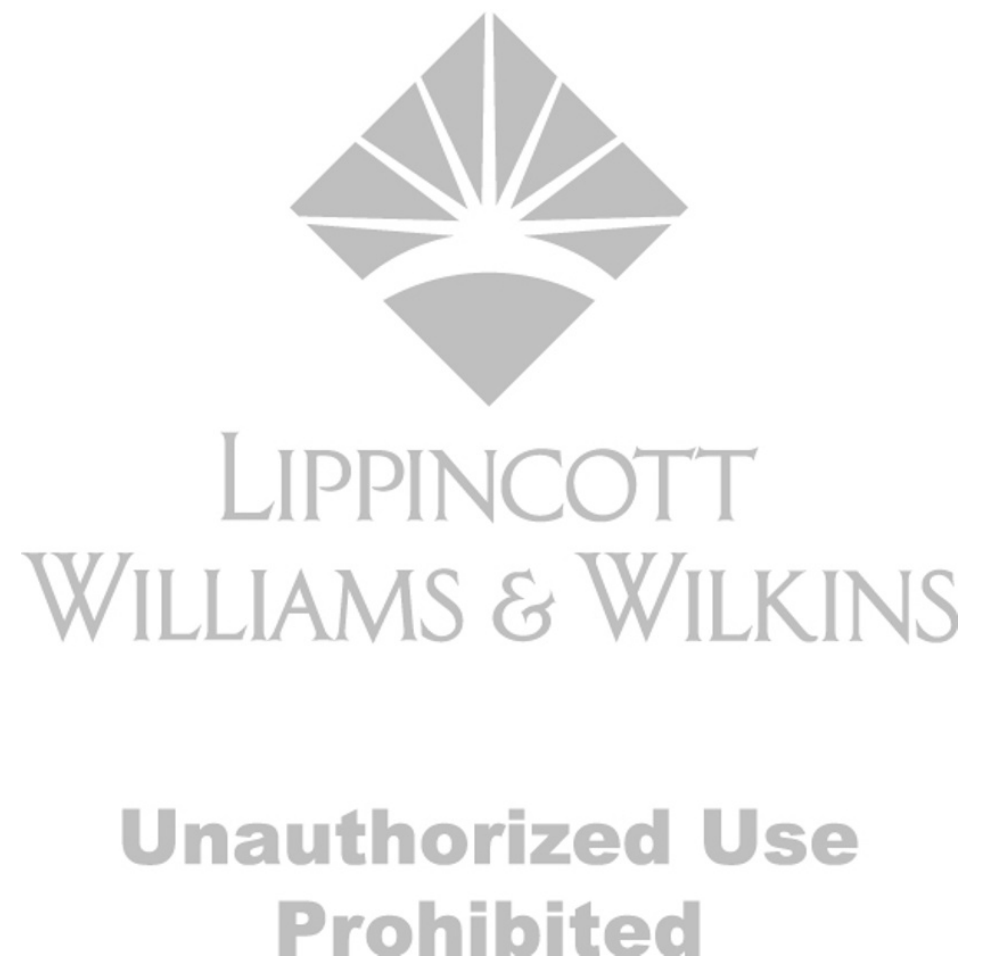

